\title{
Clinical significance of lactate clearance in patients with cardiogenic shock: results from the RESCUE registry
}

Ik Hyun Park ${ }^{1 \dagger}$, Jeong Hoon Yang ${ }^{2 \dagger}$, Woo Jin Jang ${ }^{3^{*}} \mathbb{B}^{0}$, Woo Jung Chun ${ }^{1}$, Ju Hyeon Oh ${ }^{1}$, Yong Hwan Park , Young-Guk Ko ${ }^{4}$, Cheol Woong Yu ${ }^{5}$, Bum Sung Kim ${ }^{6}$, Hyun-Joong Kim ${ }^{6}$, Hyun Jong Lee ${ }^{7}$, Jin-Ok Jeong ${ }^{8}$ and Hyeon-Cheol Gwon ${ }^{2}$

\begin{abstract}
Background: Limited data are available on the clinical significance of lactate clearance (LC) in patients with cardiogenic shock (CS). This study investigated the prognostic role of LC in CS patients.

Methods: We analyzed data from 628 patients in the RESCUE registry, a multicenter, observational cohort enrolled between January 2014 and December 2018. Univariable logistic regression analysis was performed to determine the prognostic implications of $24 \mathrm{~h} \mathrm{LC}$, and then patients were divided into two groups according to the cut-off value of $24 \mathrm{~h} \mathrm{LC}$ (high lactate clearance [HLC] group vs. low lactate clearance [LLC] group). The primary outcome was in-hospital mortality. We also assessed all-cause mortality at 12 month follow-up and compared the prognostic performance of $24 \mathrm{~h} \mathrm{LC}$ according to initial serum lactate level.

Results: In the univariable logistic regression analysis, $24 \mathrm{~h} \mathrm{LC}$ was associated with in-hospital mortality (odds ratio $0.989,95 \%$ confidence interval $[\mathrm{Cl}]$ 0.985-0.993, $p<0.001$ ), and the cut-off value for the LC of the study population was $64 \%$. The HLC group (initial $24 \mathrm{~h} \mathrm{LC} \geq 64 \%, \mathrm{n}=333$ ) had a significantly lower incidence of in-hospital death than the LLC group $(n=295)$ ( $25.5 \%$ in the HLC group vs. $42.7 \%$ in the LLC group, $p<0.001)$. During 12 months of follow-up, the cumulative incidence of all-cause death was significantly lower in the HLC group than in the LLC group (33.0\% vs. 48.8\%; hazard ratio $0.55 ; 95 \% \mathrm{Cl} 0.42-0.70 ; p<0.001)$. In subgroup analysis, $24 \mathrm{~h} \mathrm{LC}$ predicted in-hospital mortality better in patients with initial serum lactate $>5 \mathrm{mmol} / \mathrm{L}$ than in those with serum lactate $\leq 5 \mathrm{mmol} / \mathrm{L}$ (c-statistics of initial serum lactate $>5 \mathrm{mmol} / \mathrm{L}=0.782 \mathrm{vs}$. $c$-statistics of initial serum lactate $\leq 5 \mathrm{mmol} / \mathrm{L}=0.660, p=0.011)$.

Conclusions: Higher LC during the early phase of CS was associated with reduced risk of in-hospital and 12 month all-cause mortalities. Patients with $L C \geq 64 \%$ during the $24 \mathrm{~h}$ after CS onset could expect a favorable prognosis, especially those with an initial serum lactate $>5 \mathrm{mmol} / \mathrm{L}$.

Trial registration: RESCUE (REtrospective and prospective observational Study to investigate Clinical oUtcomes and Efficacy of left ventricular assist device for Korean patients with cardiogenic shock), NCT02985008, Registered December 5,2016—retrospectively and prospectively registered, https://clinicaltrials.gov/ct2/show/record/NCT02985008
\end{abstract}

\footnotetext{
*Correspondence: wj78914@gmail.com

†' k Hyun Park and Jeong Hoon Yang equally contributed to this work as first authors

${ }^{3}$ Division of Cardiology, Department of Internal Medicine, Seoul Hospital,

Ewha Womans University College of Medicine, 260, Gonghang-daero, Gangseo-gu, 07804 Seoul, Republic of Korea

Full list of author information is available at the end of the article
}

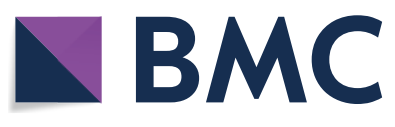

(c) The Author(s) 2021. Open Access This article is licensed under a Creative Commons Attribution 4.0 International License, which permits use, sharing, adaptation, distribution and reproduction in any medium or format, as long as you give appropriate credit to the original author(s) and the source, provide a link to the Creative Commons licence, and indicate if changes were made. The images or other third party material in this article are included in the article's Creative Commons licence, unless indicated otherwise in a credit line to the material. If material is not included in the article's Creative Commons licence and your intended use is not permitted by statutory regulation or exceeds the permitted use, you will need to obtain permission directly from the copyright holder. To view a copy of this licence, visit http://creativecommons.org/licenses/by/4.0/. The Creative Commons Public Domain Dedication waiver (http://creativeco mmons.org/publicdomain/zero/1.0/) applies to the data made available in this article, unless otherwise stated in a credit line to the data. 
Keywords: Cardiogenic shock, Lactate clearance, Prognosis

\section{Background}

Lactate has been studied over time in patients with shock, and serum lactate is an important prognostic factor that reflects decreased oxygen delivery and tissue hypoperfusion $[1,2]$. Previous studies have suggested that serum lactate clearance could be a clinically reliable surrogate for the magnitude and duration of tissue hypoxia in shock patients and demonstrated the prognostic value of lactate clearance measured at 8-48 h after initiation of shock treatment in terms of clinical outcomes [2-4]. To date, the prognostic role of lactate clearance in patients with septic shock has been reported in many studies [5, 6], including a randomized clinical trial in which lactate clearance-guided therapy was not inferior to central venous oxygen saturation-guided therapy in patients with septic shock [7]. In contrast, limited data are available on the clinical significance of lactate clearance in cardiogenic shock (CS). A small pilot study reported that $12 \mathrm{~h}$ lactate clearance $<10 \%$ was associated with significantly lower survival in CS following ST-segment elevation myocardial infarction [8]. Another study reported that a single lactate value and lactate clearance measured at $24 \mathrm{~h}$ rather than baseline lactate level were predictive for 30 day mortality in CS patients undergoing extracorporeal membrane oxygenation (ECMO) [2]. Therefore, serial measurements of lactate are recommended during shock treatment to evaluate hemodynamic status and optimize therapy $[4,9]$. Only one study has reported that lactate clearance is a better predictive marker than baseline lactate in CS [8], and other studies only analyzed specific populations of CS patients who were supported with ECMO. In these studies, the cut-off values for lactate clearance varied from 10 to $70 \%$ and were not useful in most CS patients $[2,3,8]$. Furthermore, a recent study showed that lactate measured at $8 \mathrm{~h}$ after shock onset had greater predictive value than the 8-h lactate clearance in CS patients [10]. For these reasons, the optimal clearance value and appropriate time point for measuring lactate clearance as a prognostic marker remain controversial. We evaluated the association between $24 \mathrm{~h}$ lactate clearance and clinical outcomes and compared the prognostic role of $24 \mathrm{~h}$ lactate clearance according to initial serum lactate level in patients with CS.

\section{Methods}

\section{Study design and patients}

The RESCUE (REtrospective and prospective observational Study to investigate Clinical outcomes and Efficacy of left ventricular assist device for Korean patients with cardiogenic shock; NCT02985008 at www.clinicaltrials. gov) study is a multicenter, retrospective and prospective registry of patients with CS. Between January 2014 and December 2018, 1,247 consecutive patients with CS (954 enrolled retrospectively and 293 enrolled prospectively) were recruited from 12 tertiary centers in the Republic of Korea. More detailed information about prospective and retrospective enrollment at each institute is shown in Additional file 1: Table S1. The inclusion criteria were as follows: (1) age $\geq 19$ years, (2) systolic blood pressure $<90 \mathrm{mmHg}$ for $30 \mathrm{~min}$ or need for inotrope or vasopressor support to achieve systolic blood pressure $>90 \mathrm{mmHg}$, and (3) presence of pulmonary congestion and signs of impaired organ perfusion (altered mental status, cold periphery, oliguria $<0.5 \mathrm{~mL} / \mathrm{kg} / \mathrm{hour}$ for the previous six hours, or blood lactate $>2.0 \mathrm{mmol} / \mathrm{L}$ ) [11]. Major exclusion criteria were out-of-hospital cardiac arrest, other causes of shock (hypovolemic or septic shock), and refusal of active treatment [12]. For the present study, we excluded those who died within $24 \mathrm{~h}$ of admission and those for whom serial lactate level was unavailable. Finally, 628 patients were divided into two groups according to $24 \mathrm{~h}$ lactate clearance $\geq 64 \%$ (the cut-off value of the study population, determined $24 \mathrm{~h}$ after initiation of shock treatment) or not (Fig. 1). The study protocol was approved by the institutional review board (IRB) of each hospital, and the study was conducted according to the principals of the Declaration of Helsinki. The IRBs of the participating hospitals waived the requirement for informed consent for retrospectively enrolled patients, and all prospectively enrolled patients provided written informed consent before enrollment.

\section{Data collection and study outcomes}

For the RESCUE registry, information about patient demographics, in-hospital management, laboratory data, procedural data, and outcomes was collected by independent clinical research coordinators via web-based case report forms. Additional information was obtained by further inquiry into medical records or telephone contact, if necessary [12]. Laboratory findings, such as serum creatinine and hemoglobin, exhibiting the worst values in the $24 \mathrm{~h}$ after initiation of shock treatment were collected. The primary outcome was in-hospital mortality, and the secondary outcome was all-cause mortality during 12 months of follow-up. We also analyzed the prognostic performance of $24 \mathrm{~h}$ lactate clearance according to initial serum lactate level $>5 \mathrm{mmol} / \mathrm{L}$ or not [13]. 


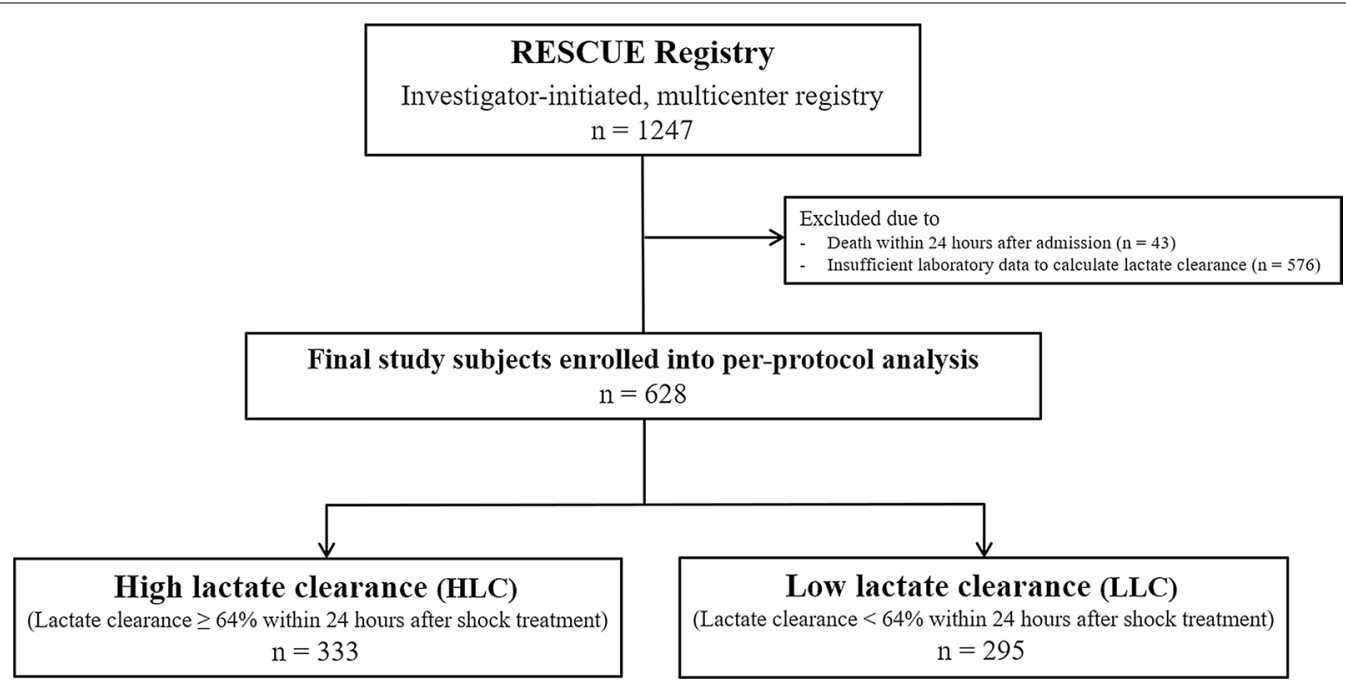

Fig. 1 Schematic illustration of study cohort selection

\section{Lactate measurement and lactate clearance}

Serum lactate values were measured serially using arterial blood gas analysis in intensive care units from the beginning of shock treatment until hemodynamically stable conditions were achieved. After that, they were measured every $24 \mathrm{~h}$. Previous studies have used various time points for lactate clearance, from 8 to $24 \mathrm{~h}$. We chose $24 \mathrm{~h}$ lactate clearance for our analysis because baseline and $24 \mathrm{~h}$ lactate values were available in our registry, and that time point has been suggested as a good predictor of mortality in patients with shock [3,14]. We calculated $24 \mathrm{~h}$ lactate clearance using the following equation: $24 \mathrm{~h}$ lactate clearance $=($ initial lactate value-lactate value $24 \mathrm{~h}$ after the initial time point)/initial lactate value [2, 9]. The prognostic role of $24 \mathrm{~h}$ lactate clearance in CS patients was investigated using a univariable logistic regression model. After it was confirmed that $24 \mathrm{~h}$ lactate clearance was associated with in-hospital mortality, the cut-off value for lactate clearance was used as a threshold to separate the groups.

\section{Statistical analysis}

Categorical variables are presented as the counts and percentages and were compared using the $x^{2}$ test or Fisher's exact test, as appropriate. Continuous variables were compared with Student's $t$-test or Mann-Whitney $U$-test and are presented as medians (interquartile ranges, 25-75th percentile) for variables lacking a normal distribution. Cumulative event rates were estimated with the Kaplan-Meier method and compared with log-rank tests. The best discriminative values were obtained from the receiver operating characteristic (ROC) curve using ROC01, a method that minimizes the distance between the ROC plot and the point $(0,1)$. The area under the receiver operating characteristic (AUROC) was calculated to quantify the accuracy of lactate clearance in predicting in-hospital mortality, and Delong's test for two correlated ROC curves was performed for comparison of the area under the curve (AUC) [15]. Univariable and multivariable logistic regression models were used to predict in-hospital mortality. Covariates that were either statistically significant on univariable analysis $(p$ value $<0.1)$ or considered clinically important were included in multivariable models. Analyzed covariates were lactate clearance, age, sex, body mass index, diabetes mellitus, hypertension, dyslipidemia, current smoking, chronic kidney disease, ischemic cardiomyopathy, and serum glucose. All probability values were two-tailed, and $p$ values $<0.05$ were considered statistically significant. Statistical analyses were performed using SPSS software, version 23 (IBM, Armonk, NY, USA).

\section{Results}

\section{Baseline characteristics}

We analyzed 628 patients, and upon using univariable logistic regression analysis to determine the prognostic implications of lactate clearance in CS, a significant association between $24 \mathrm{~h}$ lactate clearance and in-hospital mortality was observed (odds ratio [OR] 0.989, 95\% CI $0.985-0.993, p<0.001)$. The cut-off value for lactate clearance of our study population was $64 \%$ that was obtained from the ROC curve using the ROC01 method, and the study population was divided into those with lactate clearance $\geq 64 \%$ (high lactate clearance [HLC] group, $\mathrm{n}=333$ ) and those with lactate clearance $<64 \%$ (low lactate clearance [LLC] group, $n=295$ ). The baseline clinical 
characteristics of the study population are shown in Table 1 . The median age of the total study population was 66 years, and 416 patients (66.2\%) were men. There were no significant differences in demographics or co-morbidities between the HLC group and the LLC group. About half of the study population suffered from hypertension, and more than one-quarter of the study population suffered from diabetes mellitus or dyslipidemia. Ischemic cardiomyopathy was the most common cause of CS, and its incidence was similar in the two groups $(71.2 \%$ in the HLC group vs. $71.9 \%$ in the LLC group). Left ventricular ejection fraction (LVEF) at admission and lowest LVEF during follow-up were similar between the two groups ( $p=0.661$ and $p=0.405$, respectively). There were no significant differences in systolic and diastolic blood pressure $(p=0.070$ and $p=0.104)$, or heart rate $(p=0.979)$ between the two groups.

\section{Shock treatment and laboratory characteristics}

Laboratory and shock treatment characteristics according to lactate clearance are shown in Table 2. The median value of lactate clearance of the study population was 66.0\% (interquartile range 38.9-80.7). Lactate clearance of the HLC group and the LLC group were $80.0 \%$ and $36.2 \%$, respectively. The initial blood levels of hemoglobin $(\mathrm{mg} / \mathrm{dL})$, glucose $(\mathrm{mg} / \mathrm{dL})$, and lactate $(\mathrm{mmol} / \mathrm{L})$ were significantly higher in the HLC group than in the LLC group $(p=0.039, p=0.001$ and $p<0.001$, respectively). Vasoactive inotropic score was lower in the HLC group than in the LLC group $(p=0.006)$. Mechanical circulatory support and insertion of central venous line were performed similarly between the two groups $(p=0.134$ and $p=0.537$, respectively). The rate of ECMO application during the first $24 \mathrm{~h}$ of the lactate measurement period was lower in the HLC group, but the difference was not significant $(p=0.066)$. The median value of shock-toECMO time in patients who underwent ECMO within the first $24 \mathrm{~h}$ was similar between the two groups $(66 \mathrm{~min}$ vs. $77 \mathrm{~min}, p=0.267$ ). Extracorporeal cardiopulmonary resuscitation was performed less frequently in the HLC group than in the LLC group, but the difference was not significant $(p=0.077)$. The HLC group underwent

Table 1 Baseline clinical characteristics

\begin{tabular}{|c|c|c|c|}
\hline & $\begin{array}{l}\text { High lactate clearance } \\
n=333\end{array}$ & $\begin{array}{l}\text { Low lactate clearance } \\
n=295\end{array}$ & $p$ value \\
\hline Age & $65.0(55.0-75.0)$ & $68.0(56.0-78.0)$ & 0.096 \\
\hline Male & $227(68.2)$ & $189(64.1)$ & 0.278 \\
\hline Body mass index $\left(\mathrm{kg} / \mathrm{m}^{2}\right)$ & $23.0(20.8-25.7)$ & $22.9(20.4-25.7)$ & 0.900 \\
\hline Diabetes mellitus & $115(34.5)$ & $104(35.3)$ & 0.850 \\
\hline Hypertension & $161(48.3)$ & $151(51.2)$ & 0.478 \\
\hline Dyslipidemia & $87(26.1)$ & $76(25.8)$ & 0.917 \\
\hline Current smoker & $94(28.2)$ & $70(23.7)$ & 0.200 \\
\hline Chronic kidney disease & $35(10.5)$ & $38(12.9)$ & 0.355 \\
\hline Peripheral vascular disease & $19(5.7)$ & $11(3.7)$ & 0.246 \\
\hline Previous myocardial infarction & $43(12.9)$ & $37(12.5)$ & 0.889 \\
\hline Previous percutaneous coronary intervention & $48(14.4)$ & $42(14.2)$ & 0.950 \\
\hline Previous coronary artery bypass grafting & $11(3.3)$ & $7(2.4)$ & 0.486 \\
\hline Previous cerebrovascular accident & $41(12.3)$ & $27(9.2)$ & 0.203 \\
\hline Clinical presentation & & & 0.010 \\
\hline Ischemic cardiomyopathy & $237(71.2)$ & $212(71.9)$ & \\
\hline Non-ischemic cardiomyopathy & $54(16.2)$ & $55(18.6)$ & \\
\hline Pulmonary thromboembolism & $13(3.9)$ & $6(2.0)$ & \\
\hline Refractory arrhythmia & $20(6.0)$ & $5(1.7)$ & \\
\hline Other causes & $9(2.7)$ & $17(5.8)$ & \\
\hline \multicolumn{4}{|l|}{ Echocardiographic findings } \\
\hline Left ventricular ejection fraction at admission (\%) & $33.0(25.0-50.9)$ & $33.0(24.8-44.6)$ & 0.661 \\
\hline Lowest left ventricular ejection fraction (\%) & $30.0(20.0-46.0)$ & $30.0(20.5-39.9)$ & 0.405 \\
\hline Systolic blood pressure $(\mathrm{mmHg})$ & $70.0(59.0-80.0)$ & $72.0(60.0-82.0)$ & 0.070 \\
\hline Diastolic blood pressure $(\mathrm{mmHg})$ & $46.0(35.0-54.0)$ & $46.0(40.0-56.0)$ & 0.104 \\
\hline Heart rate (beat/minute) & $89.0(62.0-111.0)$ & $90.0(64.3-108.8)$ & 0.979 \\
\hline
\end{tabular}

Values are shown as $n$ (\%) or median (interquartile range) 
Table 2 Laboratory and shock treatment characteristics

\begin{tabular}{|c|c|c|c|}
\hline & $\begin{array}{l}\text { High lactate clearance } \\
n=333\end{array}$ & $\begin{array}{l}\text { Low lactate clearance } \\
n=295\end{array}$ & $p$ value \\
\hline \multicolumn{4}{|l|}{ Laboratory findings, Initial } \\
\hline Hemoglobin (mg/dL) & $12.7(10.5-14.7)$ & $12.2(10.5-14.0)$ & 0.039 \\
\hline Serum glucose (mg/dL) & $222.0(150.0-319.0)$ & $183.0(134.0-269.0)$ & 0.001 \\
\hline Total bilirubin (mg/dL) & $0.6(0.4-1.2)$ & $0.7(0.5-1.2)$ & 0.021 \\
\hline Creatinine $(\mathrm{mg} / \mathrm{dL})$ & $1.3(1.0-1.7)$ & $1.2(0.9-1.8)$ & 0.085 \\
\hline Lactate (mmol/L, at admission) & $6.9(4.7-1.0)$ & $3.7(2.3-7.1)$ & $<0.001$ \\
\hline Lactate (mmol/L, 24 h after admission) & $1.2(0.9-1.7)$ & $2.3(1.4-6.8)$ & $<0.001$ \\
\hline Lactate clearance (\%) & $80.0(72.1-86.5)$ & $36.2(0.0-53.6)$ & $<0.001$ \\
\hline NT-proBNP (pg/mL) & $5884.5(1015.5-21,827.8)$ & $5152.0(1506.5-13,628.5)$ & 0.424 \\
\hline Vasoactive inotropic score & $27.7(8.0-80.0)$ & $37.0(10.0-110.0)$ & 0.006 \\
\hline Use of venous central line & $218(65.5)$ & $200(67.8)$ & 0.537 \\
\hline Use of mechanical circulatory support & & & 0.134 \\
\hline None & $138(41.4)$ & $97(32.9)$ & \\
\hline ECMO & $126(37.8)$ & $127(43.1)$ & \\
\hline $\mathrm{IABP}$ & $51(15.3)$ & $48(16.3)$ & \\
\hline $\mathrm{ECMO}+\mathrm{IABP}$ & $18(5.4)$ & $23(7.8)$ & \\
\hline Shock-to-ECMO time $<24 \mathrm{~h}$ & $126(37.8)$ & $133(45.1)$ & 0.066 \\
\hline ECPR & $62(18.6)$ & $72(24.4)$ & 0.077 \\
\hline Continuous renal replacement therapy & $75(22.5)$ & $109(36.9)$ & $<0.001$ \\
\hline Mechanical ventilation & $219(65.8)$ & $198(67.1)$ & 0.720 \\
\hline Length of intensive care unit stay (day) & $8.0(4.0-16.5)$ & $6.0(2.0-15.0)$ & 0.002 \\
\hline Length of hospital stay (day) & $14.0(8.0-28.0)$ & $11.0(5.0-27.0)$ & 0.001 \\
\hline
\end{tabular}

Values are shown as $n$ (\%) or median (interquartile range)

ECMO extracorporeal membrane oxygenation, ECPR extracorporeal cardiopulmonary resuscitation, IABP intra-aortic balloon pump, Nt-proBNP N-terminal pro B-type natriuretic peptide

continuous renal replacement therapy less frequently than the LLC group $(p<0.001)$. The length of intensive care unit stay and hospital stay were significantly longer in the HLC group than in the LLC group ( $p=0.002$ and $p=0.001$, respectively).

\section{Clinical outcomes}

The rate of in-hospital mortality was lower in the HLC group than in the LLC group ( $25.5 \%$ vs. $42.7 \%, p<0.001)$. In-hospital cardiac mortality was observed less frequently in the HLC group than in the LLC group (16.5\% vs. $38.3 \%, p<0.001)$. There were no differences in the incidence of stroke $(2.7 \%$ vs. $1.4 \%, p=0.237)$, gastrointestinal bleeding ( $2.4 \%$ vs. $3.4 \%, p=0.459)$, or sepsis $(3.3 \%$ vs. $1.4 \%, p=0.111)$ during hospitalization between the two groups (Table 3).

During follow-up, the rates of all-cause mortality (33.0\% in the HLC group vs. $48.8 \%$ in the LLC group, hazard ratio [HR] 0.55 , 95\% confidence interval [CI] $0.42-0.70, p<0.001)$ (Fig. 2) and cardiac death $(24.3 \%$ vs. $43.7 \%$, HR $0.45,95 \%$ CI $0.34-0.60, p<0.001$ ) were significantly lower in the HLC group than in the LLC
Table 3 In-hospital clinical outcomes

\begin{tabular}{lccr}
\hline & $\begin{array}{l}\text { High lactate } \\
\text { clearance } \\
\boldsymbol{n}=\mathbf{3 3 3}\end{array}$ & $\begin{array}{l}\text { Low lactate } \\
\text { clearance } \\
\boldsymbol{n}=\mathbf{2 9 5}\end{array}$ & $\boldsymbol{p}$ value \\
\hline All-cause death & $85(25.5)$ & $126(42.7)$ & $<0.001$ \\
Cardiac death & $55(16.5)$ & $113(38.3)$ & $<0.001$ \\
Stroke & $9(2.7)$ & $4(1.4)$ & 0.237 \\
Gastrointestinal bleeding & $8(2.4)$ & $10(3.4)$ & 0.459 \\
Sepsis & $11(3.3)$ & $4(1.4)$ & 0.111
\end{tabular}

Values are shown as $n(\%)$

group. The incidence of myocardial infarction $(1.2 \%$ vs. $0.7 \%$, HR $1.38,95 \%$ CI $0.27-7.04, p=0.700)$ and cerebrovascular accident ( $0.9 \%$ vs. $1.4 \%$, HR $0.50,95 \%$ CI $0.11-2.27, p=0.371$ ) did not differ significantly between the two groups, but the rate of heart failure readmission tended to be higher in the HLC group than in the LLC group (8.4\% vs. 3.7\%, HR 1.65 , 95\% CI $0.83-$ $3.13, p=0.124$ ) (Additional file 1: Tables S2 and S3). 


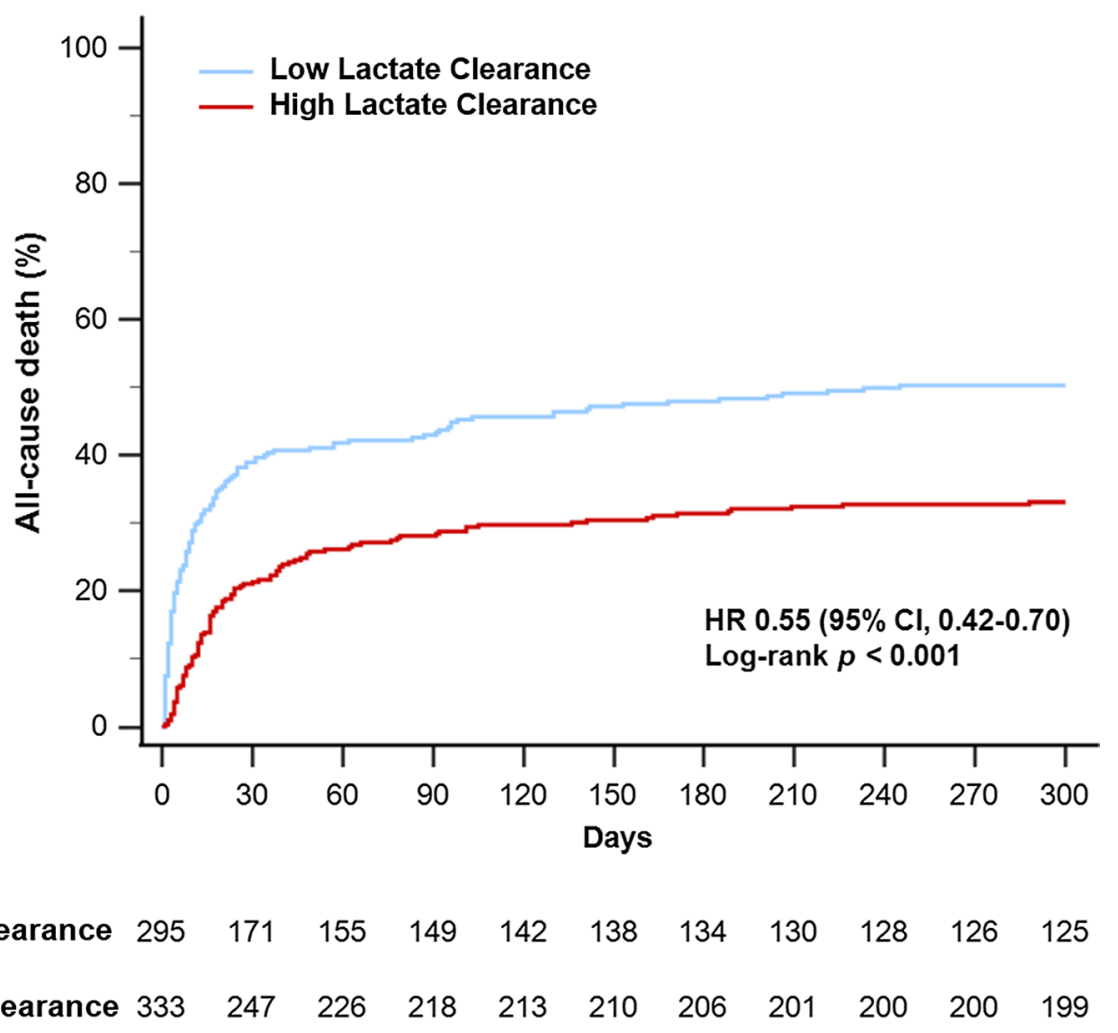

Fig. 2 The cumulative incidence of all-cause mortality during 12 month follow-up according to lactate clearance. Kaplan-Meier curves are presented to compare the cumulative incidence of all-cause mortality between the low lactate clearance group and the high lactate clearance group. Cl confidence interval, HR hazard ratio

\section{Prognostic factors of in-hospital mortality}

In multivariable logistic regression analysis, independent predictors of in-hospital mortality included $24 \mathrm{~h}$ lactate clearance $\geq 64 \%$ (OR $0.42,95 \%$ CI $0.30-0.60, p<0.001$ ), chronic kidney disease (OR 1.95, 95\% CI 1.17-3.26, $p=0.011$ ), ischemic cardiomyopathy (OR 1.52, 95\% CI 1.01-2.31, $p=0.046$ ), and baseline serum glucose above the median value of $203 \mathrm{mg} / \mathrm{dL}$ (OR 1.45, 95\% CI 1.012.08, $p=0.046$ ) (Additional file 2: Figure S1).

\section{Association of lactate clearance with clinical outcomes}

We performed a subgroup analysis to investigate the relationship between in-hospital mortality and serum lactate clearance in the first $24 \mathrm{~h}$ after initiation of shock treatment according to baseline serum lactate level. The study population was divided into two groups according to baseline serum lactate level $>5 \mathrm{mmol} / \mathrm{L}$ or not (initial serum lactate $>5 \mathrm{mmol} / \mathrm{L}$ vs. initial serum lactate $\leq 5 \mathrm{mmol} / \mathrm{L}$ ), and we calculated and compared the AUROC of $24 \mathrm{~h}$ lactate clearance to predict the in-hospital mortality of each group. In that analysis, predictive performance of $24 \mathrm{~h}$ lactate clearance for in-hospital mortality was significantly higher in patients with initial serum lactate $>5 \mathrm{mmol} / \mathrm{L}$ than in those with initial serum lactate $\leq 5 \mathrm{mmol} / \mathrm{L}(0.782$ vs. $0.660, p=0.011$ ) (Fig. 3). Subgroup analysis was performed to compare AUROC of $24 \mathrm{~h}$ lactate clearance to predict in-hospital mortality according to mechanical circulatory support within the first $24 \mathrm{~h}$ of the lactate clearance measurement period. The AUC of the overall population was 0.668 and, the IABP or medical therapy alone subgroup showed a higher AUC than the ECMO subgroup, but the difference was not significant (AUC of IABP or medical therapy alone $=0.684$ vs. AUC of $\mathrm{ECMO}=0.640$, respectively; $p=0.344$ ) (Additional file 3: Figure S2).

\section{Discussion}

We investigated the association between $24 \mathrm{~h}$ serum lactate clearance after initiation of shock treatment and clinical outcomes in patients with CS. The main finding of our study is that higher $24 \mathrm{~h}$ lactate clearance was associated with reduced risk of in-hospital and 12 month all-cause mortalities compared with lower $24 \mathrm{~h}$ lactate clearance in patients with CS. In particular, 


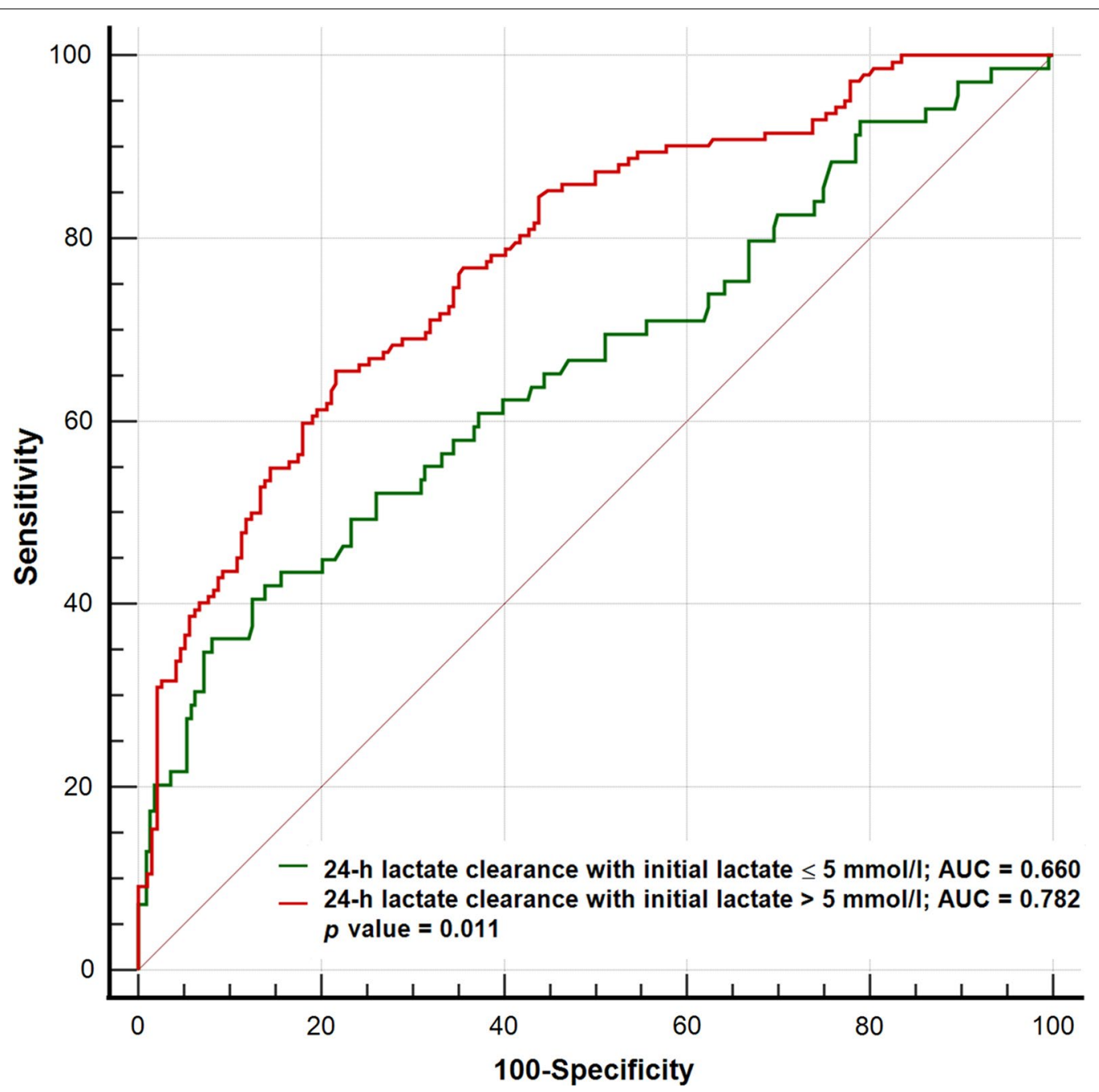

Fig. 3 ROC curves of lactate clearance to predict in-hospital mortality according to initial serum lactate level. ROC curves show the comparison of $24 \mathrm{~h}$ lactate clearance to predict in-hospital mortality according to initial serum lactate level $>5 \mathrm{mmol} / \mathrm{L}$ or not. AUC area under the curve, $R O C$ receiver operating characteristic

the prognostic role of $24 \mathrm{~h}$ lactate clearance was prominent in severe forms of CS with high initial serum lactate, suggesting that $24 \mathrm{~h}$ lactate clearance could be a treatment goal in refractory CS. To the best of our knowledge, this is the first study to examine the clinical effects of serum lactate clearance on the prognosis of diverse cardiac diseases that present with CS according to baseline serum lactate levels. Our findings correspond well with those of earlier studies that established an association between poor lactate clearance and adverse clinical outcomes.

Serum lactate varies in proportion to ongoing tissue hypoxia, and reduction of lactate level is a marker of successful resuscitation because lactate clearance indicates restored oxygen delivery [7]. Previous studies analyzing the association between lactate clearance and clinical outcome were performed mostly in patients with sepsis, and they reported that early lactate clearance above $10 \%$ was an important determinant of survival $[5,16]$. Regarding the prognostic role of lactate clearance in CS, Attanà et al. reported that $12 \mathrm{~h}$ lactate clearance $<10 \%$ identified a subset of patients at higher risk for death [8], and Slottosch et al. showed that lactate clearance across $24 \mathrm{~h}$ was predictive of 30 day mortality with a cut-off value of $68.7 \%$ in CS patients, concluding that the dynamic course of lactate is a valuable tool for predicting mortality. However, they analyzed only patients undergoing ECMO [2]. We evaluated the prognostic role of serum lactate clearance in clinical outcomes among CS patients using a large, 
multicenter, dedicated shock registry covering diverse cardiac diseases, and we identified $24 \mathrm{~h}$ lactate clearance $<64 \%$ as an indicator of higher risk for in-hospital mortality. Our threshold for lactate clearance $(24 \mathrm{~h}$ lactate clearance $\geq 64 \%$ ) could be a reliable surrogate marker for assessing successful therapy in a comprehensive cohort of CS patients, which could be used as an indicator in initial shock management.

Hyperlactatemia can be caused by hyperglycemia, catecholamines, or tissue hypoxia [17]. In our results, significant differences in vasoactive inotropic score and serum glucose were observed. These differences could be related to the initial higher lactate level in each group, and in the setting of comparing single lactate values, these variables could be confounding factors. Therefore, lactate-related criteria used to assess prognosis in CS should reflect the dynamic course of lactate levels over time $[2,8,10]$. Considering a previous study reporting that lactate clearance could not be influenced by the conditions accompanying shock [18], serum lactate clearance, which is calculated from two time points, reflects the time course of lactate level, and could show better predictive power for clinical outcomes than single lactate values. However, in a recently published study, Lee et al. classified participants as early $(<0.9 \mathrm{~h})$, intermediate $(0.9$ to $2.2 \mathrm{~h})$, and late $(>2.2 \mathrm{~h})$ according to shock-to-ECMO time, and analysis showed a $47 \%$ lower risk of 30 day mortality in the early group than in the late group, suggesting that sooner may be better [19]. On the other hand, previous studies investigating the use of mechanical circulatory support in CS reported hemodynamic improvement without mortality benefit and recommended against using active mechanical circulatory support in unselected patients due to potential complications [20, 21]. Based on these results, for risk stratification reflecting these issues, 5-stage CS classification proposed by the Society for Cardiovascular Angiography and Intervention (SCAI) [22] should be used first to discriminate patients in urgent need of ECMO, and then $24 \mathrm{~h}$ lactate clearance could be used as an indicator of high risk for adverse clinical outcomes in selective CS patients such as those in SCAI classification stage C or D. This could prevent patients in lower stages from shifting to higher stages through appropriate timing of early therapeutic intervention, since the prevalence of hemodynamic deterioration after $24 \mathrm{~h}$ increases with higher SCAI shock stages [23].

We performed additional analyses to identify subsets of patients whose lactate clearance showed better predictive power for clinical outcomes. In an analysis for developing the IABP-SHOCK II risk score, arterial blood lactate $>5 \mathrm{mmol} / \mathrm{L}$ at admission emerged as an independent predictor of 30 day mortality and was used as a key parameter of the risk prediction scoring system [13]. Since the significance of lactate clearance has not been determined according to severity of shock, we performed subgroup analysis to find a subset of CS patients whose lactate clearance exhibited better discrimination for assessing prognostic roles based on initial serum lactate level. We analyzed the accuracy of serum lactate clearance for predicting in-hospital mortality according to initial serum lactate $>5 \mathrm{mmol} / \mathrm{L}$ and found that $24 \mathrm{~h}$ lactate clearance was significantly more predictive in patients whose initial serum lactate level was greater than $5 \mathrm{mmol} / \mathrm{L}$ than it was in those whose lactate levels were less than $5 \mathrm{mmol} / \mathrm{L}$, with even better predictive ability than the single lactate value at $24 \mathrm{~h}$ after shock treatment onset. Considering that serum lactate clearance was significantly enhanced in patient treated with ECMO [24], we performed additional subgroup analysis comparing the predictive ability of $24 \mathrm{~h}$ lactate clearance for in-hospital mortality based on application of mechanical circulatory support in CS. Among those who received IABP support or medical therapy alone, serum lactate clearance predicted prognosis better than it did among those who underwent ECMO, but significance was not observed. Based on these results, $24 \mathrm{~h}$ lactate clearance could identify a subset of CS patients at high risk for adverse clinical outcomes; in particular, CS patients with high initial serum lactate level may undergo frequent assessments of arterial lactate, at least hourly or more frequent point-of-care testing [22].

Acute renal failure is a common occurrence in cardiogenic shock requiring renal replacement therapy in patients with multiple organ dysfunction. Previous studies $[25,26]$ reported that lactic acidosis could be treated successfully with renal replacement therapy, such that the serum lactate level might not reflect tissue hypoxia in cardiogenic shock. However, another study evaluating the effects of renal replacement therapy on lactate removal showed that renal replacement therapy was responsible for $<3 \%$ of total lactate clearance in critically ill patients; therefore, serum lactate level remains a reliable marker of tissue hypoxia [27]. From these various points of view, although it would not be likely to affect our results significantly, differences in the use of renal replacement therapy between the two groups could be a confounder in our study.

\section{Study limitations}

This study has several limitations. First, its design was non-randomized and observational, potentially affecting the results through selection bias and confounding 
factors. Most patients presented with an ischemic etiology, and patients with non-ischemic causes were heterogeneous and of limited sample size. Second, our registry did not include hemodynamic parameters, such as cardiac index or pulmonary capillary wedge pressure measured by a pulmonary arterial catheter. Third, removal of serum lactate could occur in the liver or kidney, so the presence of underlying disease in those organs or use of continuous renal replacement therapy could affect lactate clearance and thereby our results. Fourth, although we focused on the prognostic role of lactate clearance rather than single lactate values, significantly different serum glucose values and vasoactive inotropic scores between the two groups may have affected our results, since hyperlactatemia can be caused by hyperglycemia, or catecholamines. Finally, treatment for CS (including cardiac arrest), such as the type or amount of intravenous fluids, vasopressors, and inotropes administered and mechanical circulatory support implanted, were left to the physician's discretion, although all coronary interventions were based on guidelines from the Korean Circulation Society.

\section{Conclusions}

An initial $24 \mathrm{~h}$ serum lactate clearance $\geq 64 \%$ in CS patients was associated with lower in-hospital mortality, with a prominent association noted in those whose initial serum lactate level was $>5 \mathrm{mmol} / \mathrm{L}$. A large-scale, randomized trial is needed to confirm these findings.

\section{Abbreviations}

CS: Cardiogenic shock; ECMO: Extracorporeal membrane oxygenation; HLC: High lactate clearance; LLC: Low lactate clearance; LVEF: Left ventricular ejection fraction; ROC: Receiver operating characteristic.

\section{Supplementary Information}

The online version contains supplementary material available at https://doi. org/10.1186/s40560-021-00571-7.

Additional file 1: Table S1. Prospective and retrospective enrollments of each Institute. Table S2. 12 month follow-up outcomes. Table S3. Baseline characteristics of survivor and non-survivor.

Additional file 2: Figure S1. Predictors of in-hospital mortality.

Additional file 3: Figure S2. ROC curves of lactate clearance to predict in-hospital mortality according to the application of mechanical circulatory support.

\section{Acknowledgements}

Not applicable.

\section{Authors' contributions}

IHP, JHY, and WJJ had full access to all of the data and take responsibility for the integrity of the data and the accuracy of the data analysis. WJC, JHO, and YHP contributed to the study concept and design. All authors contributed to the acquisition, analysis, or interpretation of data. IHP, JHY, and WJJ drafted the manuscript. WJJ, JHY, JOJ, and HCG contributed to critical revision of the manuscript for important intellectual content. IHP and JHY performed statistical analysis. YGK, CWY, BSK, HJK, and HJL were responsible for study supervision. All authors gave final approval of the version to be published and agreed to be accountable for all aspects of the work, thereby ensuring that questions related to the accuracy or integrity of any part of the work are appropriately investigated and resolved. All authors read and approved the final manuscript.

Funding

This research received no external funding.

Availability of data and materials

The data used during the current study are available from the corresponding author on reasonable request.

\section{Declarations}

Ethics approval and consent to participate

The study protocol was approved by "Samsung Medical Center"Ethics Committee (approval no. 2016-03-130, April 06, 2016) and by the local ethics committee of all the study centers.

\section{Consent for publication}

The author hereby grants the publisher permission to publish the work.

\section{Competing interests}

The authors declare that they have no competing interests.

\section{Author details}

${ }^{1}$ Division of Cardiology, Samsung Changwon Hospital, Sungkyunkwan University School of Medicine, Changwon, Republic of Korea. ' Division of Cardiology, Heart Vascular Stroke Institute, Samsung Medical Center, Sungkyunkwan University School of Medicine, Seoul, Republic of Korea. ${ }^{3}$ Division of Cardiology, Department of Internal Medicine, Seoul Hospital, Ewha Womans University College of Medicine, 260, Gonghang-daero, Gangseo-gu, 07804 Seoul, Republic of Korea. ${ }^{4}$ Division of Cardiology, Severance Cardiovascular Hospital, Yonsei University College of Medicine, Seoul, Republic of Korea. ${ }^{5}$ Division of Cardiology, Korea University Anam Hospital, Seoul, Republic of Korea. ${ }^{6}$ Division of Cardiology, Konkuk University Medical Center, Seoul, Republic of Korea. ${ }^{7}$ Division of Cardiology, Sejong General Hospital, Bucheon, Republic of Korea. ${ }^{8}$ Division of Cardiology, Chungnam National University Hospital, Daejeon, Republic of Korea.

Received: 4 June 2021 Accepted: 2 September 2021

Published online: 18 October 2021

\section{References}

1. Bakker J, Postelnicu R, Mukherjee V. Lactate: Where Are We Now? Crit Care Clin. 2020;36(1):115-24

2. Slottosch I, Liakopoulos O, Kuhn E, Scherner M, Deppe AC, Sabashnikov $\mathrm{A}$, et al. Lactate and lactate clearance as valuable tool to evaluate ECMO therapy in cardiogenic shock. J Crit Care. 2017;42:35-41.

3. Park TK, Yang JH, Choi SH, Song YB, Hahn JY, Choi JH, et al. Clinical outcomes of patients with acute myocardial infarction complicated by severe refractory cardiogenic shock assisted with percutaneous cardiopulmonary support. Yonsei Med J. 2014;55(4):920-7.

4. Attana P, Lazzeri C, Picariello C, Dini CS, Gensini GF, Valente S. Lactate and lactate clearance in acute cardiac care patients. Eur Heart J Acute Cardiovasc Care. 2012;1 (2):115-21.

5. Arnold RC, Shapiro NI, Jones AE, Schorr C, Pope J, Casner E, et al. Multicenter study of early lactate clearance as a determinant of survival in patients with presumed sepsis. Shock. 2009;32(1):35-9.

6. Walker CA, Griffith DM, Gray AJ, Datta D, Hay AW. Early lactate clearance in septic patients with elevated lactate levels admitted from the emergency department to intensive care: time to aim higher? J Crit Care. 2013;28(5):832-7. 
7. Jones AE, Shapiro NI, Trzeciak S, Arnold RC, Claremont HA, Kline JA, et al. Lactate clearance vs central venous oxygen saturation as goals of early sepsis therapy: a randomized clinical trial. JAMA. 2010;303(8):739-46.

8. Attana P, Lazzeri C, Chiostri M, Picariello C, Gensini GF, Valente S. Lactate clearance in cardiogenic shock following ST elevation myocardial infarc tion: a pilot study. Acute Card Care. 2012;14(1):20-6.

9. Mungan I, Kazanci D, Bektas S, Ademoglu D, Turan S. Does lactate clearance prognosticates outcomes in ECMO therapy: a retrospective observational study. BMC Anesthesiol. 2018;18(1):152.

10. Fuernau G, Desch S, de Waha-Thiele S, Eitel I, Neumann FJ, Hennersdorf $M$, et al. Arterial Lactate in Cardiogenic Shock: Prognostic Value of Clearance Versus Single Values. JACC Cardiovasc Interv. 2020;13(19):2208-16.

11. Ponikowski P, Voors AA, Anker SD, Bueno H, Cleland JG, Coats AJ, et al. 2016 ESC Guidelines for the diagnosis and treatment of acute and chronic heart failure: The Task Force for the diagnosis and treatment of acute and chronic heart failure of the European Society of Cardiology (ESC). Developed with the special contribution of the Heart Failure Association (HFA) of the ESC. Eur J Heart Fail. 2016;18(8):891-975.

12. Park $\mathrm{H}$, Yang JH, Jang WJ, Chun WJ, Oh JH, Park YH, et al. Clinical Significance of Low-Flow Time in Patients Undergoing Extracorporeal Cardiopulmonary Resuscitation: Results from the RESCUE Registry. J Clin Med. 2020;9(11).

13. Poss J, Koster J, Fuernau G, Eitel I, de Waha S, Ouarrak T, et al. Risk Stratification for Patients in Cardiogenic Shock After Acute Myocardial Infarction. J Am Coll Cardiol. 2017;69(15):1913-20.

14. Marty P, Roquilly A, Vallee F, Luzi A, Ferre F, Fourcade $O$, et al. Lactate clearance for death prediction in severe sepsis or septic shock patients during the first 24 hours in Intensive Care Unit: an observational study. Ann Intensive Care. 2013;3(1):3

15. DeLong ER, DeLong DM, Clarke-Pearson DL. Comparing the areas under two or more correlated receiver operating characteristic curves: a nonparametric approach. Biometrics. 1988;44(3):837-45.

16. Nguyen HB, Rivers EP, Knoblich BP, Jacobsen G, Muzzin A, Ressler JA, et al. Early lactate clearance is associated with improved outcome in severe sepsis and septic shock. Crit Care Med. 2004;32(8):1637-42.

17. Jansen TC, van Bommel J, Bakker J. Blood lactate monitoring in critically ill patients: a systematic health technology assessment. Crit Care Med. 2009;37(10):2827-39.

18. Revelly JP, Tappy L, Martinez A, Bollmann M, Cayeux MC, Berger MM, et al. Lactate and glucose metabolism in severe sepsis and cardiogenic shock. Crit Care Med. 2005;33(10):2235-40.
19. Lee HH, Kim HC, Ahn CM, Lee SJ, Hong SJ, Yang JH, et al. Association Between Timing of Extracorporeal Membrane Oxygenation and Clinical Outcomes in Refractory Cardiogenic Shock. JACC Cardiovasc Interv. 2021;14(10):1109-19.

20. Thiele H, Jobs A, Ouweneel DM, Henriques JPS, Seyfarth M, Desch S, et al. Percutaneous short-term active mechanical support devices in cardiogenic shock: a systematic review and collaborative meta-analysis of randomized trials. Eur Heart J. 2017;38(47):3523-31.

21. Ouweneel DM, Eriksen E, Sjauw KD, van Dongen IM, Hirsch A, Packer EJ, et al. Percutaneous Mechanical Circulatory Support Versus Intra-Aortic Balloon Pump in Cardiogenic Shock After Acute Myocardial Infarction. J Am Coll Cardiol. 2017:69(3):278-87.

22. Baran DA, Grines CL, Bailey S, Burkhoff D, Hall SA, Henry TD, et al. SCAI clinical expert consensus statement on the classification of cardiogenic shock: This document was endorsed by the American College of Cardiology (ACC), the American Heart Association (AHA), the Society of Critical Care Medicine (SCCM), and the Society of Thoracic Surgeons (STS) in April 2019. Catheter Cardiovasc Interv. 2019;94(1):29-37.

23. Jentzer JC, van Diepen S, Barsness GW, Henry TD, Menon V, Rihal CS, et al. Cardiogenic Shock Classification to Predict Mortality in the Cardiac Intensive Care Unit. J Am Coll Cardiol. 2019;74(17):2117-28.

24. Brechot N, Hajage D, Kimmoun A, Demiselle J, Agerstrand C, Montero $S$, et al. Venoarterial extracorporeal membrane oxygenation to rescue sepsis-induced cardiogenic shock: a retrospective, multicentre, international cohort study. Lancet. 2020;396(10250):545-52.

25. Li C, Wang H, Liu N, Jia M, Hou X. The Effect of Simultaneous Renal Replacement Therapy on Extracorporeal Membrane Oxygenation Support for Postcardiotomy Patients with Cardiogenic Shock: A Pilot Randomized Controlled Trial. J Cardiothorac Vasc Anesth. 2019;33(11):3063-72.

26. Kirschbaum B, Galishoff M, Reines HD. Lactic acidosis treated with continuous hemodiafiltration and regional citrate anticoagulation. Crit Care Med. 1992;20(3):349-53.

27. Levraut J, Ciebiera JP, Jambou P, Ichai C, Labib Y, Grimaud D. Effect of continuous venovenous hemofiltration with dialysis on lactate clearance in critically ill patients. Crit Care Med. 1997;25(1):58-62.

\section{Publisher's Note}

Springer Nature remains neutral with regard to jurisdictional claims in published maps and institutional affiliations.
Ready to submit your research? Choose BMC and benefit from:

- fast, convenient online submission

- thorough peer review by experienced researchers in your field

- rapid publication on acceptance

- support for research data, including large and complex data types

- gold Open Access which fosters wider collaboration and increased citations

- maximum visibility for your research: over $100 \mathrm{M}$ website views per year

At BMC, research is always in progress.

Learn more biomedcentral.com/submissions 